\title{
In vitro eradication of citrullinated protein specific B-lymphocytes of rheumatoid arthritis patients by targeted bifunctional nanoparticles
}

Judit Pozsgay ${ }^{1,2}$, Fruzsina Babos², Katalin Uray², Anna Magyar ${ }^{1,2}$, Gergő Gyulai ${ }^{3}$, Éva Kiss³, György Nagy4, Bernadette Rojkovich ${ }^{4}$, Ferenc Hudecz ${ }^{2,5}$ and Gabriella Sármay ${ }^{1 *}$

\begin{abstract}
Background: Autoreactive B cells are crucial players in the pathogenesis of rheumatoid arthritis (RA). Autoantibodies specific for citrullinated proteins (ACPA), present in the serum of approximately $60-70 \%$ of patients, have a pathogenic role in the disease. B cell depleting therapies may result in a transient immunosuppression, increasing the risk of infections. Our aim was to develop a new therapeutic approach to selectively deplete the ACPA producing autoreactive B cells.

Methods: To target B cells synthetic citrullinated peptide derived from the $\beta$ chain of fibrin, $\beta 60-74$ Cit $60,72,74$ ( $\beta 60-74 \mathrm{Cit}$ ), the predominant epitope recognized by ACPA was used. Complement dependent cytotoxicity (CDC) was induced by a modified peptide derived from gp120 of HIV-1. To trigger CDC both the targeting peptide and the complement activating peptide were covalently coupled in multiple copies to the surface of poly (DL-lactic-co-glycolic acid) nanoparticles (NPS). Ex vivo antibody synthesis was examined by ELISA and ELISpot. CDC was tested after dead cell staining by flow cytometry.

Results: The $\beta 60-74 C i t$ peptide was selectively recognized by a small subset of B cells from RA patients having high level of peptide specific serum antibody, suggesting that the peptide can target diseased B cells. The modified gp120 peptide covalently coupled to NPs induced the formation of the complement membrane attack complex, C5b-9 in human serum. We show here for the first time that bifunctional NPs coupled to multiple copies of both the targeting peptide and the complement activating effector peptide on their surface significantly reduce $360-74$ Cit peptide specific ex vivo ACPA production, by inducing complement dependent lysis of the citrullinated peptide specific B cells of seropositive RA patients.
\end{abstract}

Conclusions: Bifunctional NPs covalently coupled to autoantigen epitope peptide and to a lytic peptide activating complement may specifically target and deplete the peptide specific autoreactive B-cells.

Keywords: anti-citrullinated protein antibodies, B cell, citrullinated peptide, complement-dependent lysis, nanoparticles, rheumatoid arthritis, targeted therapy

\footnotetext{
*Correspondence: sarmayg@elte.hu

'Department of Immunology, Eötvös Loránd University, Pázmány Péter

sétány $1 / c$, Budapest 1117, Hungary

Full list of author information is available at the end of the article
} 


\section{Background}

Rheumatoid arthritis (RA) is a chronic inflammatory autoimmune disease affecting mainly the small joints of the hands and feet causing severe tissue injury $[1,2]$. RA has a worldwide distribution with an estimated prevalence of 0.5-0.75\%. Anti-citrullinated protein antibodies (ACPA) are present in approximately $60-70 \%$ of RA patients. Citrullination is a posttranscriptional modification of arginine in certain proteins induced by peptidyl argininedeiminase enzymes [3]. ACPA sometimes appear long before the manifestation of the disease [4], and therefore detection is not only the most specific and sensitive current diagnostic tool for RA [5] but also proved to have pathogenic significance. Several target proteins for ACPA have been described, such as citrullinated filaggrin [6-9], fibrin [10-13], vimentin [14-17], enolase [18-20], collagen [21-24], and certain viral proteins [25-27]. ACPA in the inflamed synovium have been shown to associate with citrullinated protein antigens such as fibrin to form immune complexes, leading to the progression of the inflammatory process $[28,29]$.

One of the most effective biological disease-modifying anti-rheumatic drugs is rituximab, a human CD20specific chimeric monoclonal antibody, depleting CD20bearing $B$ cells [30-32]. After rituximab treatment, the B-cell number falls to an almost undetectable level at 3 months in most of the patients, and starts to rise at about 6 months [33]. Monitoring of serum antibody levels in rituximab-treated patients revealed that while titers of rheumatoid factor (RF) and anti-CCP antibodies significantly dropped, the humoral immune response towards most pathogens remained unaffected [34]. However, the transient absence of B cells may lead to an immunosuppressed state and leave the patients less protected against infections [35, 36].

Depletion of autoantigen-specific B-cell subsets recognizing the citrullinated protein epitopes might therefore be a more favorable therapeutic option. Citrulline (Cit)containing peptides corresponding to ACPA epitopes may be recognized by circulating autoreactive $B$ cells. We and others have shown that B cells from RA patients produce citrullinated epitope-specific antibodies ex vivo [37-40]. These data prompted us to introduce a Citcontaining peptide as a recognition unit to target specifically the autoreactive B cells.

The predominant synovial target for ACPA is the citrullinated fibrin [11-13]. Based on previous results identifying fibrin $\beta 60-74 \mathrm{Cit}_{60,72,74}(\beta 60-74 \mathrm{Cit})$ as the major epitope, we selected the corresponding synthetic peptide ${ }^{60}$ XPAPPPISGGGYXAX ${ }^{74}$ (X = Cit) for further experiments [10-12].

Complement-dependent lysis is one of the depletion mechanisms of B cells by rituximab, the most frequently applied B-cell depleting antibody [41, 42]. Therefore, we postulated that $\beta 60-74 \mathrm{Cit}$ peptide combined with a potentially complement activating peptide would induce specific lysis of the targeted epitope-specific B cells. Süsal et al. reported the complement activating capacity of a synthetic peptide derived from gp120 of human immunodeficiency virus type 1 (HIV-1) [43]. Based on this finding, we synthesized a novel peptide, Ac- ${ }^{233} \mathrm{C}(\mathrm{Acm}) \mathrm{NNQTFNGTGP-}$ $\mathrm{C}(\mathrm{Acm}) \mathrm{TNV}^{247}-\mathrm{K}-\mathrm{NH}_{2}$ (CNNQK), and then coupled it together with the targeting $360-74 \mathrm{Cit}$ peptide to the surface of carboxylate functionalized copolymer poly(D,Llactic-co-glycolic acid) (PLGA) nanoparticles (NPs).

The results shown here revealed that these bifunctional NPs significantly reduced ACPA production in ex vivo culture by inducing complement-dependent lysis of citrullinated fibrin $\beta$-specific B cells.

\section{Methods}

\section{Patients}

For this cross-sectional study, blood samples were collected from 170 RA patients (146 women/24 men; median age 63 years, interquartile range 51-70; median disease duration 6 years, interquartile range 3-13) with established disease at the Buda Hospital, Budapest, Hungary of Hospitaller Brothers of St John. The diagnosis of the disease was established on the basis of the revised classification criteria of the American College of Rheumatology (ACR)/ European League against Rheumatism (EULAR) [44].

Blood samples were taken with ethical permission and after the patients signed a written consent. The study has been approved by National Public Health and Medical Officer Service. Selected patients with a high level of 360 74Cit specific autoantibody (enzyme-linked immunosorbent assay (ELISA) ratios between 5 and 21 for $\beta 60-74 C i t)$ were repeatedly recruited for the functional assays (Table 1). A total of 138 age-matched healthy control sera were obtained from the 3rd Department of Medicine, Semmelweis University, Budapest, Hungary.

\section{Peptide synthesis}

All peptides were synthesized by solid-phase peptide synthesis as described previously $[11,38,45]$. The $N$ terminus of peptides was free or acetylated. $N$-terminally labeled $\beta 60-74$ peptide amides (both $\beta 60-74 C$ it and $\beta 60$ 74Arg) were synthesized using biotinyl-aminohexanoic acid $[38,45]$. The $-\mathrm{COOH}$ group on the $C$-terminus was always amidated (Table 2). Peptides were purified by semipreparative reversed-phase high-performance liquid chromatography (HPLC) and were characterized by analytical reversed-phase HPLC and electrospray ionization mass spectrometry (ESI-MS).

Preparation and characterization of bifunctional PLGA NPs Carboxylate-functionalized PLGA NPs were prepared by the nanoprecipitation method [46, 47]. The average 
Table 1 Clinical data of rheumatoid arthritis patients used in functional assays

\begin{tabular}{|c|c|c|c|c|c|c|c|c|c|c|}
\hline & Gender & Age (years) & $\begin{array}{l}\text { Disease duration } \\
\text { (years) }\end{array}$ & CRP (mg/l) & $\mathrm{RF}(\mathrm{IU} / \mathrm{ml})$ & ACPA (IU/ml) & DAS28 & ESR (mm/h) & Treatment & $\begin{array}{l}\beta 60-74 \\
\text { ELISA ratio }\end{array}$ \\
\hline Patient 1 & Female & 54 & 5 & 8.1 & 264 & 1971 & 4.99 & 15 & Sal, Afl, Lefl & 10.26 \\
\hline Patient 2 & Female & 55 & 6 & 8.2 & 265 & 1971 & 4.1 & 16 & Sal, Afl, Lefl & 11.26 \\
\hline Patient 3 & Female & 78 & 9 & 1.84 & 16.2 & 2410 & 3.7 & 10 & MTX & 15.26 \\
\hline Patient 4 & Female & 82 & 12 & 2.1 & 10.9 & Neg. & 5.05 & 47 & MTX, Med & 0.89 \\
\hline Patient 5 & Female & 62 & 8 & 0.41 & 293.6 & 2403 & 2.17 & 21 & Trexan & 0.94 \\
\hline Patient 6 & Male & 45 & 6 & 0.7 & 47 & 3200 & 0.63 & 2 & Del, Trexan & 0.74 \\
\hline Patient 7 & Female & 52 & 4 & 3.1 & 264.1 & 3200 & 4.09 & 29 & MTX, Med & 6.59 \\
\hline Patient 8 & Female & 71 & 7 & 2.3 & 15 & 1759 & 2.83 & 19 & MTX, Med & 7.41 \\
\hline Patient 9 & Female & 39 & 6 & 0.5 & 96.2 & 3073 & 2.06 & 3 & MTX & 14.81 \\
\hline Patient 10 & Female & 45 & 3 & 1.9 & 394.5 & 295 & 1.1 & 3 & MTX, Med & 9.97 \\
\hline Patient 11 & Female & 43 & 3 & 2.5 & 10.3 & 952 & 1.05 & 6 & Imuran, Metoject & 7.65 \\
\hline Patient 12 & Male & 75 & 12 & 37.8 & 51.5 & 3200 & 2.5 & 4 & Med, MTX & 6.55 \\
\hline Patient 13 & Male & 74 & 19 & 0.14 & 360.9 & 2403 & 0.84 & 5 & Roactemrat & 13.8 \\
\hline Patient 14 & Female & 45 & 5 & 4.64 & 74.4 & 2991 & 4.01 & 9 & Medrol, Trexan & 20.97 \\
\hline Patient 15 & Female & 64 & 7 & 3.1 & 15.6 & 951 & 2.22 & 13 & Lefl, Med & 3.58 \\
\hline Patient 16 & Female & 63 & 5 & 6.7 & 673 & 964 & 2.1 & 20 & Sal, Metoject & 9.56 \\
\hline Patient 17 & Male & 70 & 9 & 9.3 & 25 & 3200 & 2.63 & 5 & MTX, Sal, Med & 14.35 \\
\hline Patient 18 & Female & 76 & 24 & 19.7 & 225 & 2132 & 7.97 & 42 & Med, MTX & 8.31 \\
\hline Patient 19 & Female & 41 & 1 & 2.3 & 129 & 765 & 3.41 & 4 & Med & 6.98 \\
\hline Patient 20 & Female & 60 & 9 & 47.86 & 65.3 & 349 & 5.39 & 97 & Med, Nebivolol & 6.35 \\
\hline
\end{tabular}

ACPA anti-citrullinated protein antibodies, Afl aflamin, CRP C-reactive protein, DAS28 Disease Activity Score of 28 joints, Del delagil, ELISA enzyme-linked immunosorbent assay, ESR erythrocyte sedimentation rate, Lefl leflunomid, Med medrol, MTX methotrexate, Neg negative, RF rheumatoid factor, Sal salazopyrin

hydrodynamic diameter, polydispersity, and zeta potential of PLGA NPs were characterized by dynamic light scattering and zeta potential measurements. The NPs were dispersed in doubly distilled water, finally containing $1.6 \times$ $10^{11} \mathrm{NPs} / \mathrm{ml}$. The average diameter of NPs was 160 $180 \mathrm{~nm}$, and each NP contained approximately 4-5000 carboxyl groups available for covalent binding of peptides.

NPs were converted in Milli-Q, Merck KGaA, Darmstadt, Germany water to PLGA-active ester derivative with high excess $N$-hydroxysuccinimide and 1-ethyl-3-(3-dimethylaminopropyl)-carbodiimide. The $N$-hydroxysuccinimide-activated particles were covalently linked to a 1:1 (mol:mol) mixture of CNNQK and $\beta 60-74$ Cit peptides. It should be noted that the targeting $\beta 60-74$ Cit peptide was coupled at its $N$-terminal $\alpha$-amino group, while the CNNQK peptide was coupled at its $C$-terminal $\varepsilon$-amino group of Lys residue to the NPs. This attachment strategy resulted in uniformly oriented peptides of the two types. The efficient coupling of

Table 2 Sequences of peptides used for the ELISA experiments and for the bifunctional nanoconstructs

\begin{tabular}{|c|c|c|}
\hline Peptides & Code & Amino acid sequence ${ }^{a}$ \\
\hline Fibrin $\beta 60-74$ & $\beta 60-74 \operatorname{Arg}$ & $\mathrm{H}^{-60}{ }^{\mathrm{RPAPPPISGGGYRAR}}{ }^{74}-\mathrm{NH}_{2}$ \\
\hline Fibrinß60-74Cit $60,72,74$ & $\beta 60-74$ Cit & $\mathrm{H}^{6}{ }^{6} \mathbf{X}$ PAPPPISGGGYXAX $\mathbf{X}^{74}-\mathrm{NH}_{2}$ \\
\hline Biot-fibrinß60-74 & Biot- $\beta 60-74$ Arg & Biot $^{60}{ }^{6 P A P P P I S G G G Y R A R}{ }^{74-} \mathrm{NH}_{2}$ \\
\hline Biot-fibrin $\beta 60-74$ Cit $_{60,72,74}$ & Biot- $\beta 60-74$ Cit & Biot- $^{60} \mathbf{X}$ PAPPPISGGGYXAX $\mathbf{X}^{74}-\mathrm{NH}_{2}$ \\
\hline HIV-1 gp120 $233-247$ Complement activating peptide & CNNK & $\mathrm{Ac}^{233} \mathrm{C}(\mathrm{Acm}) \mathrm{NNKTFNGTGPC}(\mathrm{Acm}) \mathrm{TNV}^{247}-\mathrm{NH}_{2}$ \\
\hline HIV-1 gp120 $233-247$ Q-substituted complement activating peptide & CNNQ & $\mathrm{Ac}^{-233} \mathrm{C}(\mathrm{Acm}) \mathrm{NNQ} \mathbf{T F N G T G P C}(\mathrm{Acm}) \mathrm{TNV}^{247}-\mathrm{NH}_{2}$ \\
\hline HIV-1 gp120 $233-247$ Q-substituted complement activating peptide with C-terminal K & CNNQK & $\mathrm{Ac}^{233} \mathrm{C}(\mathrm{Acm}) \mathrm{NNQTFNGTGPC}(\mathrm{Acm}) \mathrm{TNV}^{247}-\mathrm{K}_{-} \mathrm{NH}_{2}$ \\
\hline
\end{tabular}

${ }^{\mathrm{a} S t a n d a r d}$ one-letter code for amino acid residues: $\mathrm{X}$ citrulline, $\mathrm{Ac}$ - acetyl group, $-\mathrm{NH}_{2}$ amid group, $\mathrm{Acm}$ acetamidomethyl group, Biot

biotinyl-aminohexanoyl group

ELISA enzyme-linked immunosorbent assay, HIV-1 human immunodeficiency virus type 1

Bold letters stand for modified amino acids that are not present in the natural sequences 
peptides to NPs was controlled after enzymatic digestion by HPLC/mass spectrometry (data not shown).

\section{B-cell purification}

Peripheral blood mononuclear cells (PBMCs) were isolated from healthy donors and RA patients as described previously [38]. For the peptide-specific antibody secretion assay, B cells were purified by negative selection using RosetteSep antibody cocktail (Stem Cell Technologies, Vancouver, BC, Canada), according to the manufacturer's instructions. The purity of the resulting B-cell population was $80-85 \%$. To stimulate antibody secretion, $10^{6} \mathrm{~B}$ cells $/ \mathrm{ml}$ were cultured for 5 days in the presence of $7.5 \mu \mathrm{g} / \mathrm{ml}$ phosphorothioated unmethylated CpG oligodeoxynucleotide (ODN-2006, 5'-tcgtcgttttgtcgttttg tcgt'-3'; Sigma Aldrich Co., St. Louis, MO, USA) and $1.5 \mathrm{ng} / \mathrm{ml}$ human recombinant B-cell activating factor of the tumor necrosis family (BAFF; ImmunoTools $\mathrm{GmbH}$, Friesoythe, Germany). The combined stimuli with CpG and BAFF were applied since Toll-like receptor TLR9 activation by CpG renders human B cells more sensitive to the effects of BAFF by increasing the membrane-bound BAFF that may enhance Bcell proliferation, differentiation, and autoantibody production [48].

A higher purity of B cells is needed for the peptidebinding and for the cytotoxicity assays. $\mathrm{B}$ cells were therefore purified by negative selection using magnetic bead-activated cell sorting (MACS) according to the manufacturer's protocol (Miltenyi Biotec, Auburn, CA, USA). The purity of the resulting B-cell population was $85-98 \%$. B cells $\left(10^{6} / \mathrm{ml}\right)$ were cultured with $1 \mu \mathrm{g} / \mathrm{ml} \mathrm{CpG}, 50 \mathrm{ng} /$ $\mathrm{ml}$ interleukin (IL)-2, and $50 \mathrm{ng} / \mathrm{ml} \mathrm{IL-21} \mathrm{(ImmunoTools}$ $\mathrm{GmbH}$ ) for 48 hours to increase the frequency of activated memory B cells.

\section{ELISA}

In the serum ELISA, $N$-terminally biotinylated $\beta 60$ 74Cit and $360-74$ Arg were used. Biotinylated peptides (1 $\mu \mathrm{g} / \mathrm{ml}$ in phosphate-buffered saline (PBS)) were bound to a NeutrAvidin ( $5 \mu \mathrm{g} / \mathrm{ml}$ in PBS; Pierce Biotechnology, Rockford, IL, USA) precoated plate [45]. ELISA ratios were calculated (optical density (OD) with 360-74Cit/OD with $360-74 \mathrm{Arg}$ ) and compared between groups. The cutoff value was calculated from ELISA ratios of 138 healthy samples (means of ELISA ratios $\pm 2 *$ standard deviation $(\mathrm{SD})$ ).

Antibody secretion was determined by ELISA from the supernatant of in vitro stimulated B cells, with plates coated as already described. The peptide-specific antibodies were detected by horseradish peroxidase (HRP)-conjugated anti-human IgG + M (Jackson Immunoresearch Laboratories Inc., West Grove, PA, USA).

\section{Detection of $\beta 60-74$ Cit peptide-specific B cells by flow cytometry}

Purified B cells were cultured with $1 \mu \mathrm{g} / \mathrm{ml} \mathrm{CpG}$ and $10 \mathrm{ng} / \mathrm{ml} \mathrm{IL-2}$ for 48 hours to increase the frequency of memory B cells. The biotinylated $\beta 60-74$ Cit or $\beta 60-74$ Arg peptides were coupled to NeutrAvidin-labeled yellow-green microspheres $(1 \mu \mathrm{m}$ diameter; Thermo Fisher Scientific Inc., Waltham, MA, USA). The peptide-coated fluorescent microspheres were added to $B$ cells at 100-fold excess and the samples were incubated for 1 hour at $4{ }^{\circ} \mathrm{C}$. The peptide-specific B cells were detected with a FACSCalibur flow cytometer (Becton-Dickinson, Franklin Lakes, NJ, USA) and data were analyzed using FlowJo software (Tree Star Inc., Ashland, OR, USA).

\section{Detection of IgG secreting cells by enzyme-linked immunospot assay}

PBMCs were cultured in RPMI-1640 containing $10 \%$ fetal calf serum in the presence of $10 \mathrm{ng} / \mathrm{ml}$ recombinant IL-2 and $1 \mu \mathrm{g} / \mathrm{ml}$ R848 polyclonal activator provided with the enzyme-linked immunospot assay (ELISpot) kit (Mabtech, Stockholm, Sweden). The cells were harvested at the 3rd day, and incubated for 1 hour with the bifunctional PLGA NPs at 1000-fold excess. After removing the unbound NPs, the cells were incubated at $37{ }^{\circ} \mathrm{C}$ for 30 minutes in the presence of $1 \%, 3 \%, 5 \%$ and $10 \%$ pooled normal human serum (NHS) as a complement source or in heat-inactivated serum. After washing, $4 \times$ $10^{5}$ PBMCs were transferred into the wells of ELISpot plates precoated with the $360-74$ Cit peptides and with anti-IgG, respectively. The spots were developed after 18 hours by biotinylated detection monoclonal antibodies, streptavidin HRP, and substrate (Mabtech). The frequency of IgG-specific and peptide-specific IgG-producing cells was determined using a C.T.L. Immunospot analyzer (CTL-Europe GmbH, Bonn, Germany).

\section{Measuring the complement activating capacity of the modified HIV-1 gp120 peptides}

Complement activation by the modified gp120 peptides ${ }^{233} \mathrm{C}(\mathrm{Acm}) \mathrm{NNKTFNGTGPC}(\mathrm{Acm}) \mathrm{TN}^{247}$ (CNNK) and ${ }^{233} \mathrm{C}(\mathrm{Acm}) \mathrm{NNQTFNGTGPC}(\mathrm{Acm}) \mathrm{TNV}^{247}$ (CNNQ) (Table 2) was tested by ELISA. High-binding ELISA plates (Greiner bio-one $\mathrm{GmbH}$, Frickenhausen, Germany) were coated with $10 \mu \mathrm{g} / \mathrm{ml}$ peptide or with $100 \mu \mathrm{g} / \mathrm{ml} \operatorname{IgG}$ as a control. Pooled human serum or heat-inactivated serum was added at 1:50 dilution for 1 hour. The deposited complement C3 cleavage products were detected by HRPconjugated anti-human-C3 (MP Biomedicals, Solon, OH, USA), while $\mathrm{C} 4$ and $\mathrm{C} 9$ were detected by anti-human $\mathrm{C} 4$ and C9 antibodies (Merck KGaA, Darmstadt, Germany), respectively, followed by HRP-conjugated anti-goat IgG. The C1q depleted serum and the C3-depleted serum was purchased from Merck KGaA. 
To test the complement activating capacity of the CNNQK-coated and 360-74Cit-coated bifunctional NPs, the release of the soluble complement components (SC5b-9) was measured. Then $10^{9}$ NPs were incubated in $100 \mu \mathrm{l} 50 \%$ human serum for 1 hour at $37^{\circ} \mathrm{C}$ and SC5b-9 was determined in the supernatant by the SC5b9 Plus kit (Quidel, San Diego, CA, USA) according to the manufacturer's instruction.

\section{Cytotoxicity assay}

B cells $\left(10^{6} \mathrm{~B}\right.$ cells $\left./ \mathrm{ml}\right)$ were prestimulated with $1 \mu \mathrm{g} / \mathrm{ml}$ CpG and $10 \mathrm{ng} / \mathrm{ml} \mathrm{IL-2} \mathrm{for} 48$ hours. The bifunctional, fluorescein-containing NPs covered with the targeting $\beta 60-74$ Cit and the effector CNNQK peptides were added to $\mathrm{B}$ cells at 5000 -fold excess, and then the samples were incubated for 1 hour on ice. After washing, the cells were incubated with $20 \%$ pooled human serum as a complement source or heat-inactivated serum for $30 \mathrm{mi}-$ nutes at $37{ }^{\circ} \mathrm{C}$, and then were stained with $\mathrm{TO}-\mathrm{PRO}^{\circ}-3$ (Thermo Fisher Scientific Inc.) for 15 minutes to detect damaged cells. The dead $360-74$ Cit peptide-specific B cells were detected as the FL1/FL4 double-positive population with a FACSCalibur flow cytometer (BectonDickinson), and data were analyzed using FlowJo software (Tree Star Inc.).

\section{Statistical analysis}

For the statistical analysis of data, the Mann-Whitney test (Fig. 1a), analysis of variance (ANOVA) (Figs. 1c, 2 and $3 \mathrm{a}, \mathrm{b}, \mathrm{d}$ ) and the two-tailed $t$ test (Figs. 3c, 4 and 5) were used and the results were analyzed with GRAPHPAD PRISM 4 software (GraphPad Software, La Jolla, CA, USA). In all tests, $p<0.05$ was considered significant.

\section{Results}

Recognition of Cit-containing fibrin $\beta$ peptide by serum antibodies and by B cells of RA patients

Sera samples of 170 diagnosed RA patients and 138 healthy blood donors were screened by indirect ELISA. The ELISA ratios and the receiver operating characteristic curve are shown in Fig. 1a and b, respectively. With our experimental set up, at a $95 \%$ specificity level $\beta 60-74$ Cit peptide was recognized by serum antibodies from $52 \%$ of RA patients.

The presence of the serum antibodies specific for $\beta 60$ 74Cit suggests that we should find memory B cells in the blood of RA patients with identical specificity. To increase the binding avidity of the peptide we applied neutravidinlabeled polystyrene microspheres $(1 \mu \mathrm{m}$ diameter $)$ loaded with a high-intensity fluorescent dye, coating its surface with Biot- $\beta 60-74$ Cit or Biot- $\beta 60-74$ Arg. B cells from selected anti-360-74Cit peptide-positive or peptide-negative RA patients and from healthy controls were prestimulated to increase the frequency of memory B cells [49]. Microspheres coated with $360-74$ Arg bound to B cells at the same level as the uncoated controls, while microspheres covered with the $360-74$ Cit peptide specifically bound to a small but significant proportion of B cells from RA patients, but not to B cells from healthy volunteers, or from 360-74Cit antibody-negative patients (Fig. 1c).

In vitro secretion of $\beta 60-74 C$ it peptide-specific antibodies by $B$ cells of RA patients

To reveal whether ex vivo stimulation of $B$ cells results in 360-74Cit peptide-specific antibody secretion, purified B cells from selected RA patients with high serum antibody level and from healthy controls were cultured for 5 days in the presence of the TLR9 agonist, CpG ODN,
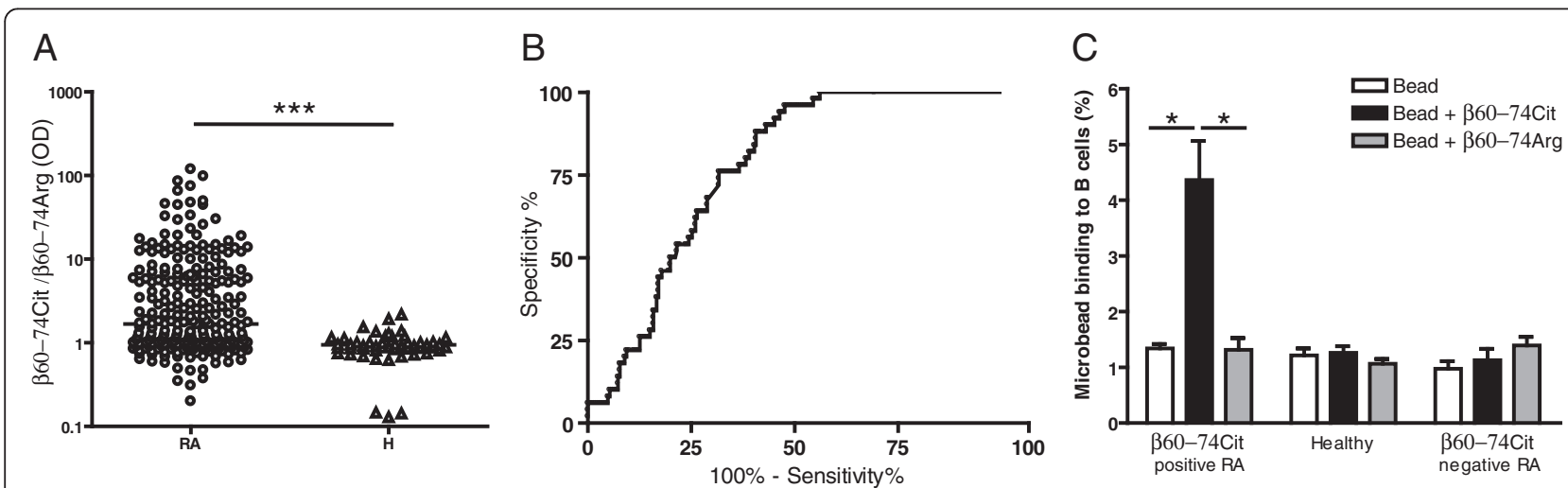

Fig. 1 Recognition of Cit-containing peptide epitope of fibrin $\beta$ chain by antibodies in sera of RA patients and healthy blood donors $\mathbf{a}$, $\mathbf{b}$ and by isolated B cells $\mathbf{c}$. a Reactivities of RA $(n=170)$ or healthy $(n=138)$ serum samples with N-terminally bitotinylated $\beta 60-74 C$ it vs. $\beta 60-74 A r g$ bound to neutravidin precoated plates. ELISA ratios were calculated (OD with $\beta 60-74$ Cit /OD with $\beta 60-74 \mathrm{Arg}$ ). Data were analyzed with the Mann-Whitney test, and the median OD ratio of RA samples was 1.68, interquartile range $0.95-6.33$, and the median OD ratio of healthy samples was 0.91 , interquartile range 0.81-1.07 (*** $<0.001$ ). b Receiver operating characteristic curve analysis, area under the curve value for $\beta 60-74$ Cit: 0.7661. c Binding of $\beta 60-74 C$ it and $\beta 60-74$ Arg-coated fluorescent microspheres to prestimulated B cells from $\beta 60-74$ Cit seropositive or seronegative RA patients and from healthy individuals ( $n=3 /$ group, ELISA ratios of the selected $\beta 60-74$ Cit seropositive RA patients were between 10 and 15 ). Bars show means \pm SD, ${ }^{*} p<0.05$. OD optical density, $R A$ rheumatoid arthritis, $H$ healthy 


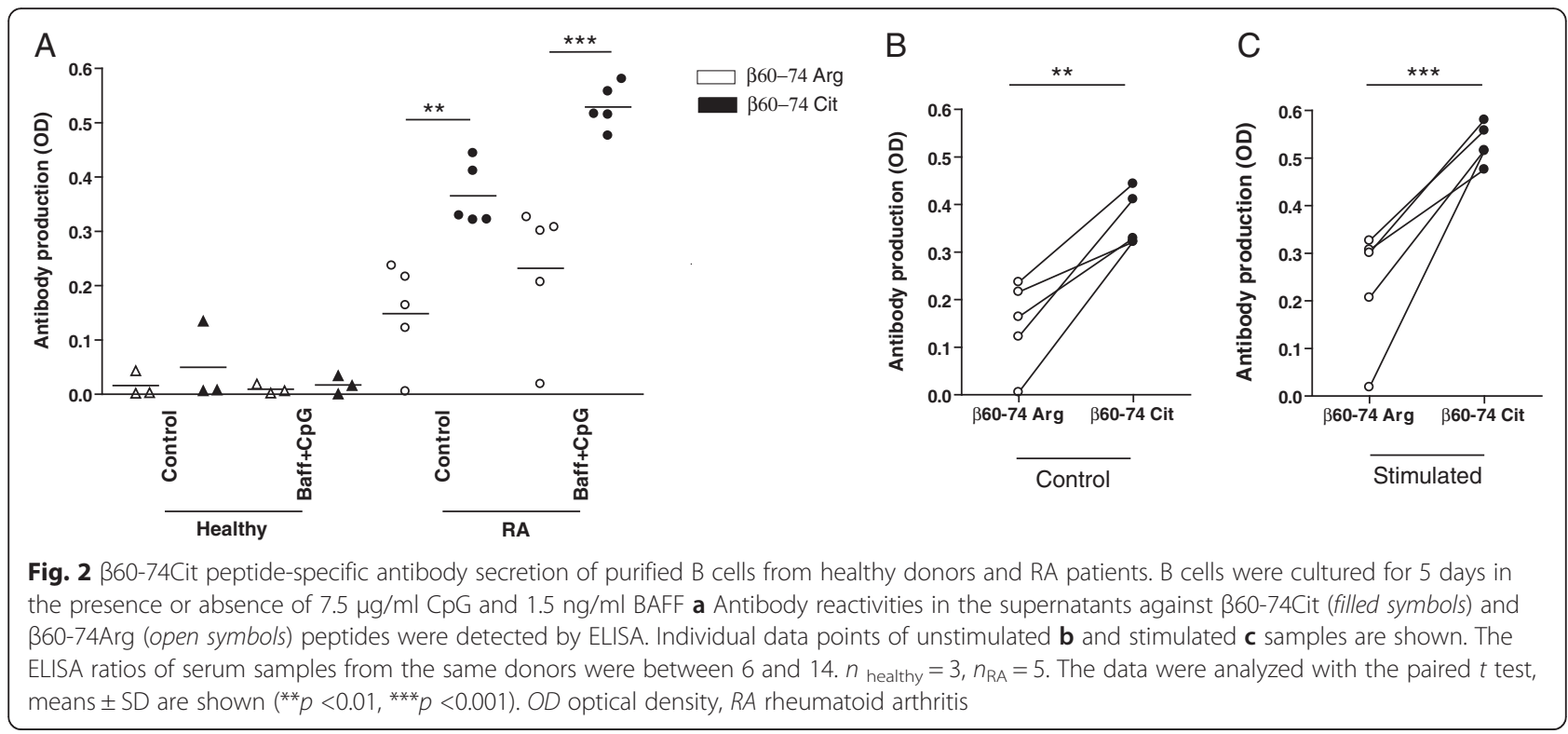

and BAFF. Antibody production was followed by testing the presence of native $\beta 60-74 \mathrm{Arg}$-specific and $\beta 60$ 74Cit-specific IgG in the culture supernatants. B cells from healthy individuals did not produce a considerable amount of peptide-specific antibodies, while the patients'
B cells secreted IgG specific for the $\beta 60-74$ Cit peptide even without stimulation. A significantly lower level of B60-74Arg specific IgG was detected in all samples. CpG and BAFF double stimuli increased the $\beta 60-74$ Cit peptide-specific IgG secretion (Fig. 2a). Individual data

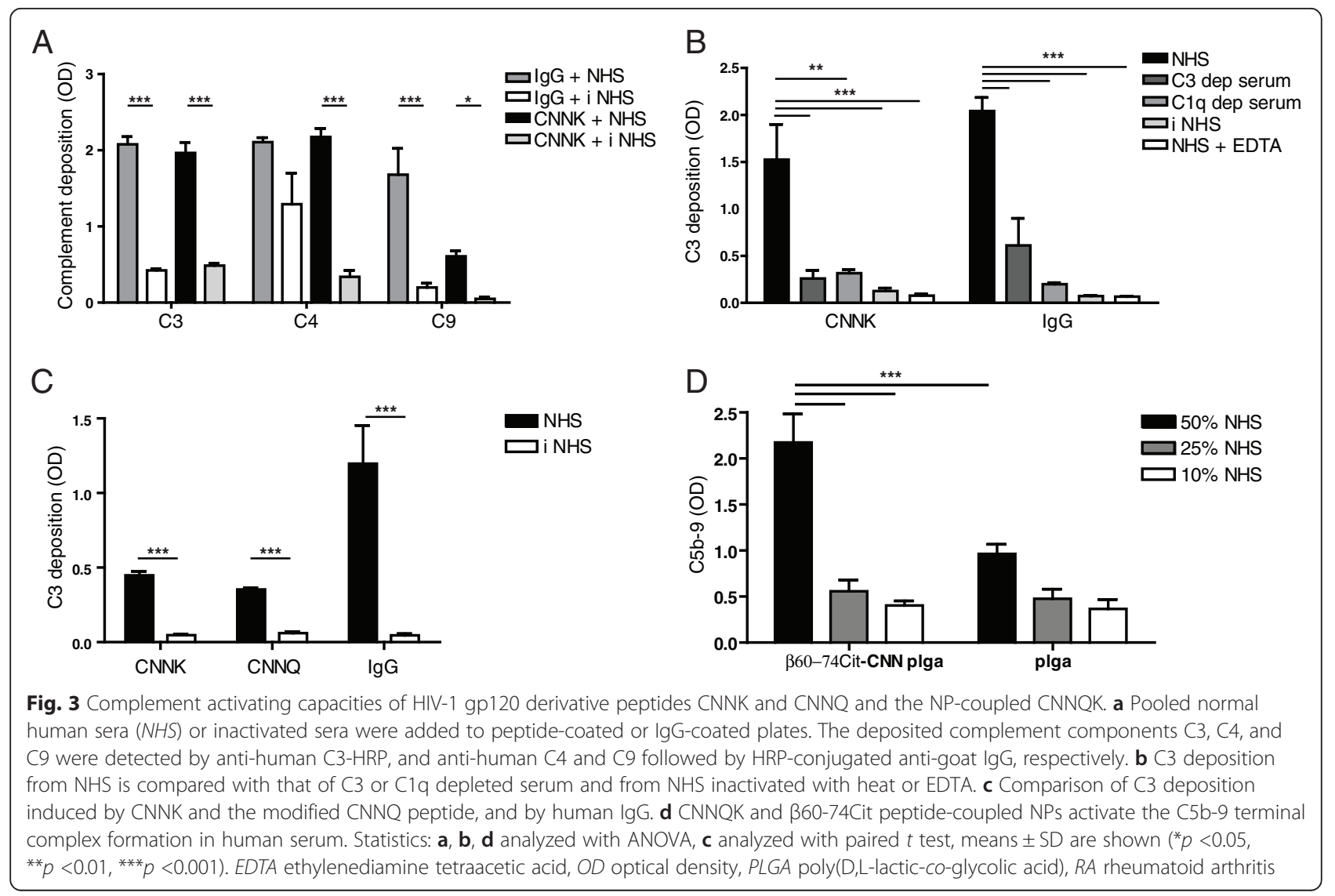




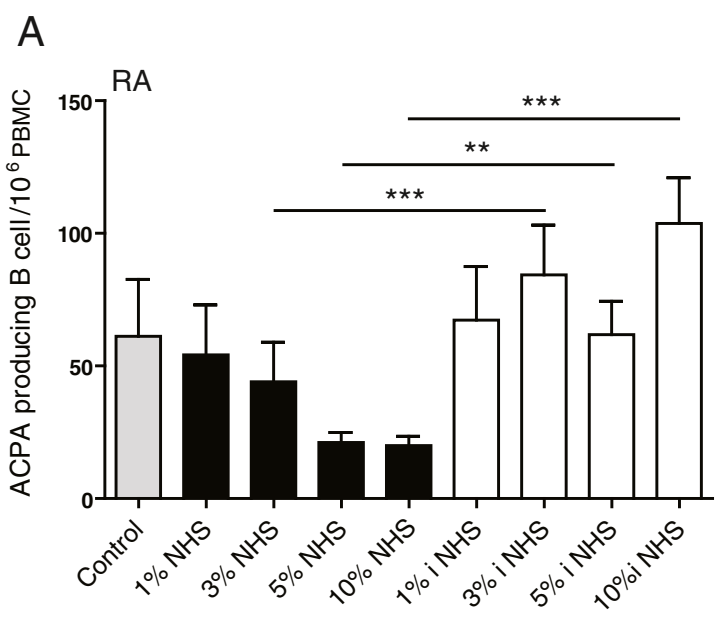

B

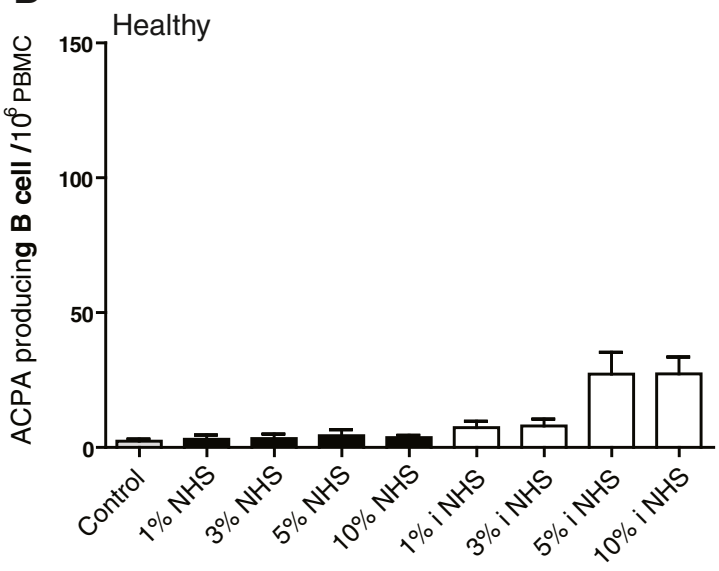

C

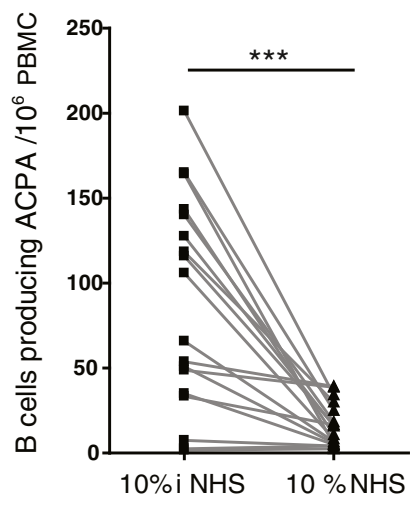

D

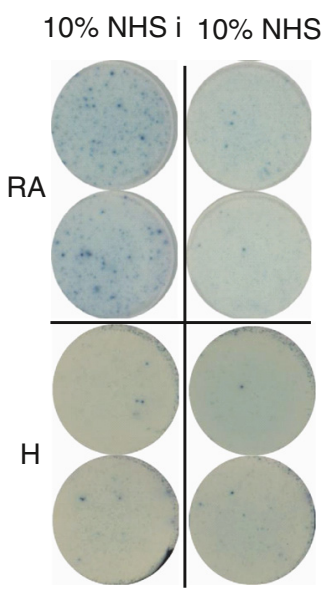

Fig. 4 B60-74Cit and CNNQK peptide-coated bifunctional NPs suppress ex vivo synthesis of $\beta 60-74 C i t$ specific antibodies in the presence of active complement in human sera. a PBMCs from RA patients ( $n=17$, ELISA ratios for $\beta 60-74$ Cit between 6 and 21$)$ and $\mathbf{b}$ from healthy donors $(n=5)$ were stimulated with the TLR7/TLR8 agonist, R848, and IL-2 for 72 hours, and then the bifunctional NPs were added to the harvested cells followed by normal human sera (NHS) or heat-inactivated NHS (iNHS) at different concentrations. The number of $\beta 60-74$ Cit-specific lgG-producing plasma cells was counted by ELISPot. c Individual data of RA patients at $10 \%$ iNHS and NHS are shown. d Representative ELISpot images. Statistics: $\mathbf{a}, \mathrm{c}$ analyzed with paired $t$ test, means \pm SD are shown $\left({ }^{* *} p<0.01,{ }^{* * *} p<0.001\right)$. ACPA anti-citrullinated protein antibody, PBMC peripheral blood mononuclear cell, $R A$ rheumatoid arthritis, $H$ healthy

sets are shown in Fig. 2b (unstimulated cells) and Fig. 2c (B cells stimulated with $\mathrm{CpG}$ and BAFF).

\section{Analysis of complement activating capacity of the modified gp120-derived synthetic peptides and the bifunctional NPs}

In order to induce complement-dependent lysis of autoreactive $\mathrm{B}$ cells, our aim was to combine the targeting properties of 360 -74Cit peptide with a peptide inducing complement activation. We shortened the corresponding gp120 peptide [43] at the C-terminal end with protected Cys residues and obtained the peptide CNNK (Table 2). CNNK had a comparable complement activating property with IgG regarding $\mathrm{C} 3$ and $\mathrm{C} 4$ deposition, while a somewhat lower level of $\mathrm{C} 9$ deposition was detected that was still significantly higher as compared with heatinactivated sera (Fig. 3a).

$\mathrm{C} 1 \mathrm{q}$ is essential to trigger the classical complement activation pathway. Neither the CNNK peptide nor IgG induced deposition of $\mathrm{C} 3$ from C1q-depleted as well as from $\mathrm{C} 3$-depleted sera, indicating that the classical pathway is activated. EDTA by chelating $\mathrm{Ca}^{2+}$ inhibited complement activation, and thereby $\mathrm{C} 3$ deposition (Fig. 3b).

For the coupling of CNNK peptide to the surface of NPs first we had to substitute 236Lys with Gln. The new peptide CNNQ had identical reactivity with CNNK, both inducing C3 deposition on peptide-coated surfaces (Fig. 3c).

CNNQ peptide was coupled to NPs via the $\varepsilon$ amino group of an added C-terminal Lys (CNNQK). The complement activation property of the bifunctional NPs covalently coupled to both $\beta 60-74 \mathrm{Cit}$ and CNNQK 

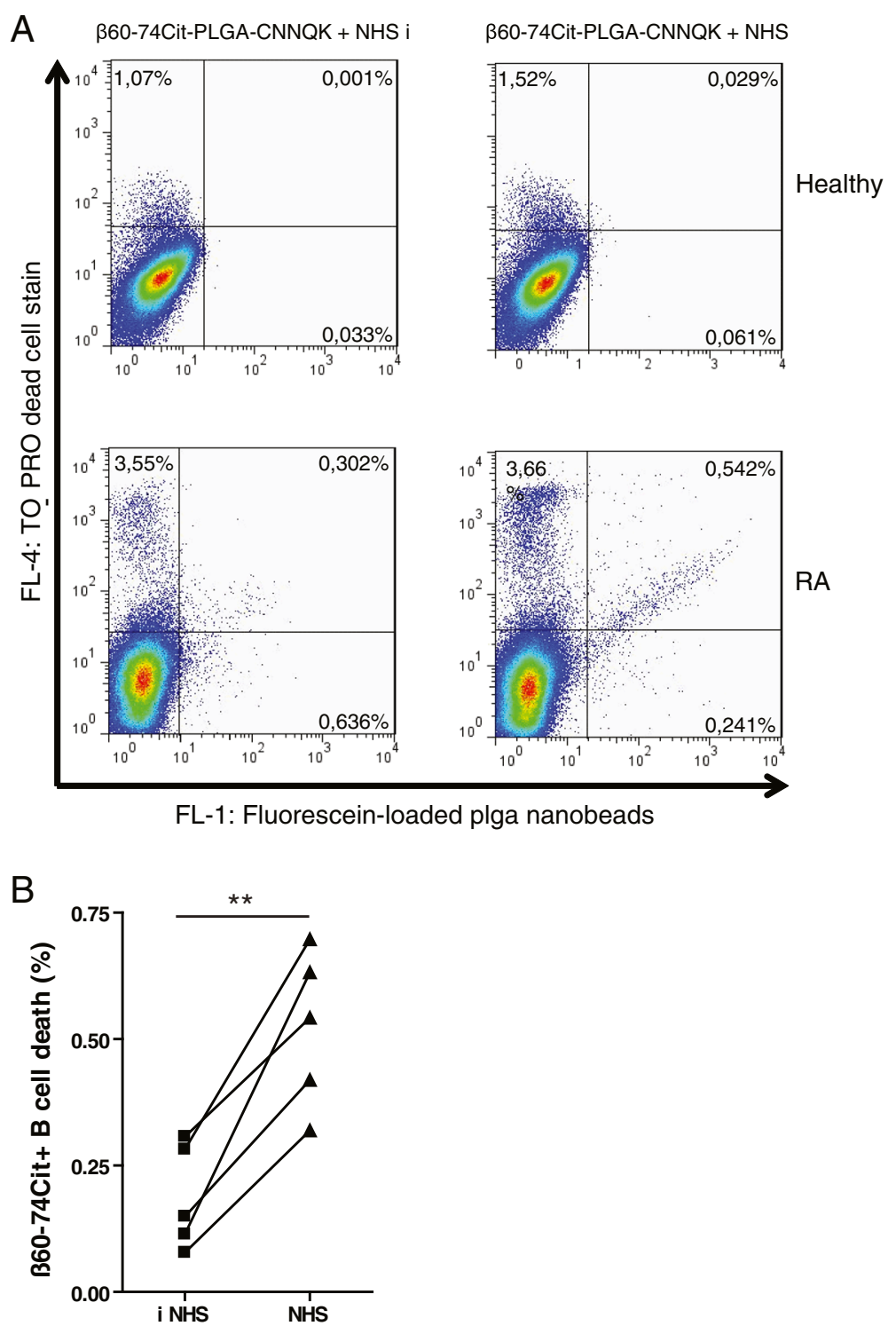

Fig. 5 Complement-dependent lysis of $\beta 60-74$ Cit peptide-specific B cells induced by bifunctional PLGA NPs in the presence of NHS as measured by flow cytometry. a Upper panel: representative figure of a healthy donor, lower panel: typical result with an RA patient. The binding of fluorescein-loaded NPs was detected in channel 1, dead cells were detected after TO-PRO staining in channel 4. The B60-74Cit-positive, killed B cells are detected in the right upper quadrant of the dot plot. $\mathbf{b}$ Individual data of five RA patients. ELISA ratios of sera of the same RA patients were between 5 and 19. Data were analyzed with paired $t$ test, means \pm SD are shown $\left({ }^{* *} p<0.01\right)$. iNHS heat-inactivated normal human sera, NHS normal human sera, PLGA poly(D,L-lactic-co-glycolic acid)

peptides was tested by monitoring the formation of soluble C5b-9 terminal complex in human serum (Fig. 3d). Bifunctional NPs induced a significantly higher C5b-9 release as compared with noncoated NPs, indicating that the former activate the terminal components of complement system.

\section{B60-74Cit and CNNQK peptide-coated bifunctional NPs suppress $\beta 60-74 C i t-s p e c i f i c$ antibody synthesis}

To study whether bifunctional NPs indeed target B cells that specifically recognize the $\beta 60-74 \mathrm{Cit}$ peptide, PBMCs from selected RA patients having high $360-74$ Cit peptide-specific serum antibody level and from healthy donors were stimulated with the TLR7/TLR8 agonist, R848, and IL-2 for 72 hours, and then the harvested cells were incubated with the bifunctional NPs, followed by the addition of pooled human sera or inactivated sera at different concentrations. The number of peptide-specific IgG-producing plasma cells was estimated by ELISpot on the next day. Stimulation of B cells from RA patients but not from healthy individuals by TLR-mediated signals induced the differentiation of plasma cells that 
secreted 360-74Cit peptide-specific antibodies (Fig. 4a, b). In the presence of active complement, depending on serum concentration, the bifunctional NPs significantly reduced the number of $\beta 60-74 \mathrm{Cit}$ peptide-specific plasma cells, while in heat-inactivated serum NPs had no effect (Fig. 4a). The individual peptide-specific spot numbers in samples treated with $10 \%$ heat-inactivated or active sera (Fig. 4c) and representative ELISpot images (Fig. 4d) are shown. Nonspecific IgG secretion was not affected by the bifunctional NPs (data not shown).

\section{The bifunctional NPs induce complement-dependent lysis of $\beta 60-74$ Cit peptide-specific $B$ cells}

Purified B cells of RA patients and from healthy controls were incubated with fluorescein-loaded bifunctional NPs. Following the treatment with active or heatinactivated human sera NPs, binding to live and dead B cells was detected by flow cytometry. The binding of fluorescein-loaded NPs was detected in FL1, while cells stained with the dead cell indicator To-Pro-3 were spotted in FL4. The small B-cell subset in RA samples showing double staining in the presence of active complement represents the $360-74$ Cit-specific $B$ cells killed by the bifunctional NPs. This population was only detected in anti-Cit fibrin $\beta$-positive RA patients and was completely absent in healthy individuals (Fig. 5a). The number of dead cells was significantly lower in samples treated with heatinactivated as compared with active sera, indicating the complement-dependent lysis of $360-74$ Cit-specific B cells (Fig. 5b).

\section{Discussion}

We report here for the first time that the fibrin $\beta 60$ 74Cit peptide-specific B cells from RA patients can be specifically deleted in vitro by a bifunctional NP-based construct, where the $360-74$ Cit epitope and a HIV-1 gp120 $233-247$ derivative peptide activating complement were covalently linked to NPs. Controlled clinical trials have shown that B-cell depletion therapies such as rituximab led to significant benefit for RA patients, indicating that $\mathrm{B}$ cells have a crucial role in the disease etiology [30-32, 34]. Although rituximab therapy only moderately affects pre-existing antibody titers, the patients are transiently immunosuppressed and have an increased risk of infection [34-36]. Therapies based on specific targeting and elimination of the autoantigen (e.g., citrullinated protein/peptide)-specific B cells would therefore be most advantageous.

Circulating plasma blasts/cells from RA patients secrete ACPA in vitro, indicating that in addition to the memory B-cell pool specific for citrullinated proteins/ peptides there is an ongoing immune response in ACPA seropositive patients $[39,40]$. Previous experiments revealed that the three Cit-containing fibrin $\beta_{60-74}$ peptide represents the major ACPA epitope on the $\beta$ chain of fibrin [11]. In our cohort $52 \%$ of RA patients have shown serum antibody positivity with an average ELISA ratio around 10. Based on these data we selected patients with high antibody level for the cellular and functional assays.

Next, purified B cells from these selected patients were examined for $360-74$ Cit peptide positivity and for in vitro antibody production. Since the number of peptidepositive cells was expected to be low [40], and serum antibodies have low affinity to the citrullinated peptides [50,51], the detection of peptide-specific cells is difficult. Therefore we stimulated B cells via TLR9, promoting proliferation independently from B-cell receptor and increasing the frequency of memory cells [49]. To increase the avidity of peptide binding to B cells and to improve detection of binding, we applied fluorescent microspheres coated with neutravidin and the biotinylated $360-74$ Cit peptide. Under these conditions we detected $2-3 \%$ specific binding, indicating that $360-74$ Cit peptide-positive B cells are present in the circulation of RA patients and thus could be targeted by this peptide.

We also measured antibody secretion in the supernatants of ex vivo activated B cells, and in agreement with earlier results $[39,40]$ we found that even nonstimulated $B$ cells from RA patients but not from healthy individuals secrete $360-74 \mathrm{Cit}$ peptide-specific antibodies that were significantly elevated due to stimulation with $\mathrm{CpG}$. Interestingly, a low level of antibody production was observed with the control peptide ( $(360-74 \mathrm{Arg})$ as well but that was not influenced by stimulation and was significantly lower in each sample as compared with the citrullinated peptide samples.

Depleting activity of antibody therapeutics is based on Fc-dependent effector functions such as antibodydependent cytotoxicity and complement activating capacity inducing complement-dependent lysis [41, 42]. In order to combine the $360-74 \mathrm{Cit}$ peptide mimicking the autoantigen with an entity destroying the targeted $B$ cells by complement-dependent lysis, we applied the HIV-1 gp120 derivative peptide CNNK. This peptide stimulated the classical pathway of complement activation and initiated the deposition of $\mathrm{C} 3, \mathrm{C} 4$, and $\mathrm{C} 9$ to the peptidecoated surfaces, at a degree comparable with IgG.

For targeted delivery of the effector, complement activating peptide and to increase the binding avidity of $\beta 60$ 74Cit peptide to B cells, we utilized biodegradable PLGA NPs that are not immunogenic, are nontoxic for cells, and are applicable under in vivo conditions [47]. NPs covered both with the effector peptide CNNQK and the targeting epitope peptide $360-74 \mathrm{Cit}$ were able to initiate the formation of soluble C5b-9 complex in human serum corresponding to the membrane attack complex, suggesting that the bifunctional NPs could induce cell lysis. 
We postulated that these bifunctional NPs would indeed destroy B cells specific for the targeting compound, B60-74Cit peptide. Experiments testing the cytotoxic effect have shown that a small population $(0.7-0.9 \%)$ of $B$ cells from RA patients having high serum antibody level bound NPs and a subset of these cells was killed in the presence of active complement.

Finally, as a proof of concept, the effect of bifunctional NPs was tested on ex vivo $360-74 C$ it peptide-specific antibody secretion. Depending on the serum concentration and the presence of active complement, the treatment of stimulated PBMCs with bifunctional NPs significantly reduced the number of $360-74$ Cit peptidespecific IgG-producing plasma cells in cultures obtained from RA patients. The number of plasma cells synthesizing nonspecific IgG in response to CpG stimuli was not modified significantly, demonstrating that the $360-74 \mathrm{Cit}$ epitope-specific autoreactive B cells are selectively depleted by the bifunctional NPs. Moreover, since this treatment diminishes citrullinated peptide-specific autoantibody production in vitro, it may result in a lower rate of autoreactive immune complex formation in seropositive patients, thus reducing inflammation. This pilot study only shows in vitro depletion of B cells recognizing a single epitope of fibrin, $360-74 \mathrm{Cit}$. We suppose that a mixture of lytic NPs should be applied simultaneously, targeting several different autoantigen epitope-specific B cells. Since an autoantigen-specific depleting therapy affects only a small subset, it should leave the rest of the B cells unattended and enable them to respond to microbial stimuli.

\section{Conclusion}

Taken together, the data of this pilot study demonstrate that biodegradable NPs armed with an epitope peptide (B60-74Cit) targeting B cells from RA patients and with an effector peptide (CNNQK) activating complement can destroy autoreactive, $\beta 60-74$ Cit-specific B cells in vitro. These data indicate that such constructs might be suitable for future development of personalized autoantigen-specific depletion therapy.

\footnotetext{
Abbreviations

ACPA: Anti-citrullinated protein antibodies; ACR: American College of Rheumatology; ANOVA: Analysis of variance; BAFF: B-cell activating factor; Cit: Citrulline; ELISA: Enzyme-linked immunosorbent assay; ELISpot: Enzyme-linked immunospot assay; ESI-MS: Electrospray ionization mass spectrometry; EULAR: European League against Rheumatism; HIV-1: Human immunodeficiency virus-1; HPLC: High-performance liquid chromatography; HRP: Horseradish peroxidase; IL: Interleukin; MACS: Magnetic bead-activated cell sorting; NHS: Normal human serum; NP: Nanoparticle; OD: Optical density; PBMC: Peripheral blood mononuclear cell; PBS: Phosphate-buffered saline; PLGA: poly(D,L-lacticco-glycolic acid); RA: Rheumatoid arthritis; RF: Rheumatoid factor; SD: Standard deviation; TLR: Toll-like receptor.
}

\section{Competing interests}

The authors declare that they have no competing interests.

\section{Authors' contributions}

JP prepared the cells and carried out the experiments with sera and cell samples, performed ELISA, flow cytometry, and ELISpot, and drafted the manuscript. FB and KU synthesized the Cit and Arg-containing fibrin peptides and the complement activating peptides, respectively, and helped to draft the manuscript. AM contributed to peptide synthesis, coupled the peptides to NPs and analyzed the product, and revised the manuscript. GG prepared, purified, and characterized the NPs and helped to draft the manuscript. ÉK designed and coordinated the work with NPS and helped to draft the manuscript. GN and BR provided the blood samples from RA patients and collected their clinical parameters, and helped to revise the manuscript. FH participated in the design of the study and in its coordination and revised the manuscript. GS designed and coordinated the study and revised the manuscript. All authors read and approved the final manuscript.

\section{Acknowledgements}

The authors want to acknowledge Prof. G Serre, Dr L Nogueira, and Dr M Sebbag for the fruitful discussions and advice, and Dr M Jozsi for the C1q depleted serum, the SC5b-9 ELISA kit, and consultation. The authors would like to thank Dr Zoltan Prohaszka for providing the healthy control serum samples and Dr Gitta Schlosser for the analysis of peptides on the surface of NPS. This work was supported by the National Research Development and Innovation Office (OMFB-0134, 0135, 136/-2010), Hungarian National Science Fund (NFU-OTKA CK80689 and OTKA NK 104846), and MTA-MEDinPROT to GS, by OTKA 104928 and OTKA NK 105898 to ÉK, and the European Union and the European Social Fund provided financial support to the project under grant agreement number TAMOP 4.2.1./B-09/1/KMR-2010-0003.

\section{Author details \\ ${ }^{1}$ Department of Immunology, Eötvös Loránd University, Pázmány Péter sétány 1/c, Budapest 1117, Hungary. ${ }^{2}$ MTA-ELTE Research Group of Peptide Chemistry, Hungarian Academy of Sciences, Eötvös Loránd University, Budapest 1117, Hungary. ${ }^{3}$ Laboratory of Interfaces and Nanostructures, Institute of Chemistry, Eötvös Loránd University, Budapest 1117, Hungary. ${ }^{4}$ Department of Rheumatology, Polyclinic of the Hospitaller Brothers of St. John of God, Budapest 1023, Hungary. ${ }^{5}$ Department of Organic Chemistry, Eötvös Loránd University, Budapest 1117, Hungary.}

Received: 22 October 2015 Accepted: 4 January 2016

Published online: 16 January 2016

\section{References}

1. Gabriel SE. The epidemiology of rheumatoid arthritis. Rheum Dis Clin North Am. 2001;27:269-81.

2. Klareskog L, Ronnelid J, Lundberg K, Padyukov L, Alfredsson L. Immunity to citrullinated proteins in rheumatoid arthritis. Annu Rev Immunol. 2008;26:651-75.

3. Yamada R, Suzuki A, Chang X, Yamamoto K. Peptidylarginine deiminase type 4: identification of a rheumatoid arthritis-susceptible gene. Trends Mol Med. 2003;9:503-8.

4. Brink M, Hansson M, Mathsson L, Jakobsson PJ, Holmdahl R, Hallmans G, et al. Multiplex analyses of antibodies against citrullinated peptides in individuals prior to development of rheumatoid arthritis. Arthritis Rheum. 2013;65:899-910.

5. Willemze A, Bohringer S, Knevel R, Levarht EW, Stoeken-Rijsbergen G, Houwing-Duistermaat JJ, et al. The ACPA recognition profile and subgrouping of ACPA-positive RA patients. Ann Rheum Dis. 2012;71:268-74.

6. Perez ML, Gomara MJ, Ercilla G, Sanmarti R, Haro I. Antibodies to citrullinated human fibrinogen synthetic peptides in diagnosing rheumatoid arthritis. J Med Chem. 2007;50:3573-84

7. Nogueira L, Sebbag M, Vincent C, Arnaud M, Fournie B, Cantagrel A, et al. Performance of two ELISAs for antifilaggrin autoantibodies, using either affinity purified or deiminated recombinant human filaggrin, in the diagnosis of rheumatoid arthritis. Ann Rheum Dis. 2001;60:882-7.

8. Vincent C, Nogueira L, Sebbag M, Chapuy-Regaud S, Arnaud M, Letourneur $\mathrm{O}$, et al. Detection of antibodies to deiminated recombinant rat filaggrin by enzyme-linked immunosorbent assay: a highly effective test for the diagnosis of rheumatoid arthritis. Arthritis Rheum. 2002;46:2051-8

9. Girbal-Neuhauser E, Durieux JJ, Arnaud M, Dalbon P, Sebbag M, Vincent C, et al. The epitopes targeted by the rheumatoid arthritis-associated 
antifilaggrin autoantibodies are posttranslationally generated on various sites of (pro)filaggrin by deimination of arginine residues. J Immunol. 1999;162:585-94.

10. Sebbag M, Moinard N, Auger I, Clavel C, Arnaud J, Nogueira L, et al. Epitopes of human fibrin recognized by the rheumatoid arthritis-specific autoantibodies to citrullinated proteins. Eur J Immunol. 2006;36:2250-63.

11. Cornillet M, Sebbag M, Verrouil E, Magyar A, Babos F, Ruyssen-Witrand A, et al. The fibrin-derived citrullinated peptide beta60-74Cit(6)(0), (7)(2), (7)(4) bears the major ACPA epitope recognised by the rheumatoid arthritis-specific anticitrullinated fibrinogen autoantibodies and anti-CCP2 antibodies. Ann Rheum Dis. 2014;73:1246-52.

12. Iobagiu C, Magyar A, Nogueira L, Cornillet M, Sebbag M, Arnaud J, et al. The antigen specificity of the rheumatoid arthritis-associated ACPA directed to citrullinated fibrin is very closely restricted. J Autoimmun. 2011;37:263-72.

13. Masson-Bessiere C, Sebbag M, Girbal-Neuhauser E, Nogueira L, Vincent C, Senshu T, et al. The major synovial targets of the rheumatoid arthritisspecific antifilaggrin autoantibodies are deiminated forms of the alpha- and beta-chains of fibrin. J Immunol. 2001;166:4177-84.

14. Bang H, Egerer K, Gauliard A, Luthke K, Rudolph PE, Fredenhagen G, et al. Mutation and citrullination modifies vimentin to a novel autoantigen for rheumatoid arthritis. Arthritis Rheum. 2007:56:2503-11.

15. Nicaise Roland P, Grootenboer Mignot S, Bruns A, Hurtado M, Palazzo E, Hayem $G$, et al. Antibodies to mutated citrullinated vimentin for diagnosing rheumatoid arthritis in anti-CCP-negative patients and for monitoring infliximab therapy. Arthritis Res Ther. 2008;10:R142.

16. Van Steendam K, Tilleman $K$, Deforce D. The relevance of citrullinated vimentin in the production of antibodies against citrullinated proteins and the pathogenesis of rheumatoid arthritis. Rheumatology. 2011;50:830-7.

17. Harre U, Georgess D, Bang H, Bozec A, Axmann R, Ossipova E, et al. Induction of osteoclastogenesis and bone loss by human autoantibodies against citrullinated vimentin. J Clin Invest. 2012;122:1791-802.

18. Kinloch A, Tatzer V, Wait R, Peston D, Lundberg K, Donatien $\mathrm{P}$, et al. Identification of citrullinated alpha-enolase as a candidate autoantigen in rheumatoid arthritis. Arthritis Res Ther. 2005:7:R1421-9.

19. Lundberg K, Kinloch A, Fisher BA, Wegner N, Wait R, Charles P, et al. Antibodies to citrullinated alpha-enolase peptide 1 are specific for rheumatoid arthritis and cross-react with bacterial enolase. Arthritis Rheum. 2008:58:3009-19.

20. Mahdi H, Fisher BA, Kallberg H, Plant D, Malmstrom V, Ronnelid J, et al. Specific interaction between genotype, smoking and autoimmunity to citrullinated alpha-enolase in the etiology of rheumatoid arthritis. Nat Genet. 2009;41:1319-24

21. Burkhardt $H$, Sehnert B, Bockermann R, Engstrom A, Kalden JR, Holmdahl R. Humoral immune response to citrullinated collagen type II determinants in early rheumatoid arthritis. Eur J Immunol. 2005:35:1643-52.

22. Suzuki A, Yamada R, Ohtake-Yamanaka M, Okazaki Y, Sawada T, Yamamoto K. Anti-citrullinated collagen type I antibody is a target of autoimmunity in rheumatoid arthritis. Biochem Biophys Res Commun. 2005;333:418-26.

23. Snir $O$, Widhe M, Hermansson M, von Spee C, Lindberg J, Hensen S, et al. Antibodies to several citrullinated antigens are enriched in the joints of rheumatoid arthritis patients. Arthritis Rheum. 2010;62:44-52.

24. Haag S, Schneider N, Mason DE, Tuncel J, Andersson IE, Peters EC, et al. Identification of new citrulline-specific autoantibodies, which bind to human arthritic cartilage, by mass spectrometric analysis of citrullinated type II collagen. Arthritis Rheumatol. 2014:66:1440-9.

25. van Venrooij WJ, van Beers JJ, Pruijn GJ. Anti-CCP antibodies: the past, the present and the future. Nat Rev Rheumatol. 2011;7:391-8.

26. Anzilotti C, Merlini G, Pratesi F, Tommasi C, Chimenti D, Migliorini P. Antibodies to viral citrullinated peptide in rheumatoid arthritis. J Rheumatol. 2006;33:647-51.

27. Pratesi F, Tommasi C, Anzilotti C, Puxeddu I, Sardano E, Di Colo G, et al. Antibodies to a new viral citrullinated peptide, VCP2: fine specificity and correlation with anti-cyclic citrullinated peptide (CCP) and anti-VCP1 antibodies. Clin Exp Immunol. 2011:164:337-45.

28. Laurent L, Anquetil F, Clavel C, Ndongo-Thiam N, Offer G, Miossec P, et al. lgM rheumatoid factor amplifies the inflammatory response of macrophages induced by the rheumatoid arthritis-specific immune complexes containing anticitrullinated protein antibodies. Ann Rheum Dis. 2015;74:1425-31.

29. Anquetil F, Clavel C, Offer G, Serre G, Sebbag M. IgM and IgA rheumatoid factors purified from rheumatoid arthritis sera boost the Fc receptor-and complement-dependent effector functions of the disease-specific anti-citrullinated protein autoantibodies. J Immunol. 2015;194:3664-74.

30. Jacobi AM, Dorner T. Current aspects of anti-CD20 therapy in rheumatoid arthritis. Curr Opin Pharmacol. 2010;10:316-21.

31. Martinez-Gamboa L, Brezinschek HP, Burmester GR, Dorner T. Immunopathologic role of $B$ lymphocytes in rheumatoid arthritis: rationale of B cell-directed therapy. Autoimmun Rev. 2006:5:437-42.

32. Sibilia J, Gottenberg JE, Mariette X. Rituximab: a new therapeutic alternative in rheumatoid arthritis. Joint Bone Spine. 2008;75:526-32.

33. Teng YK, Wheater G, Hogan VE, Stocks P, Levarht EW, Huizinga TW, et al. Induction of long-term B-cell depletion in refractory rheumatoid arthritis patients preferentially affects autoreactive more than protective humoral immunity. Arthritis Res Ther. 2012;14:R57.

34. Bingham 3rd CO, Looney RJ, Deodhar A, Halsey N, Greenwald M, Codding C, et al. Immunization responses in rheumatoid arthritis patients treated with rituximab: results from a controlled clinical trial. Arthritis Rheum. 2010;62:64-74.

35. Anolik JH, Friedberg JW, Zheng B, Barnard J, Owen T, Cushing E, et al. B cell reconstitution after rituximab treatment of lymphoma recapitulates $B$ cell ontogeny. Clin Immunol. 2007;122:139-45.

36. Gottenberg JE, Ravaud P, Bardin T, Cacoub P, Cantagrel A, Combe B, et al. Risk factors for severe infections in patients with rheumatoid arthritis treated with rituximab in the autoimmunity and rituximab registry. Arthritis Rheum. 2010;62:2625-32

37. Reparon-Schuijt CC, van Esch WJ, van Kooten C, Schellekens GA, de Jong BA, van Venrooij WJ, et al. Secretion of anti-citrulline-containing peptide antibody by B lymphocytes in rheumatoid arthritis. Arthritis Rheum. 2001;44:41-7.

38. Szarka E, Babos F, Magyar A, Huber K, Szittner Z, Papp K, et al. Recognition of new citrulline-containing peptide epitopes by autoantibodies produced in vivo and in vitro by B cells of rheumatoid arthritis patients. Immunology. 2014;141:181-91.

39. Bellatin MF, Han M, Fallena M, Fan L, Xia D, Olsen N, et al. Production of autoantibodies against citrullinated antigens/peptides by human $B$ cells. J Immunol. 2012;188:3542-50.

40. Kerkman PF, Fabre E, van der Voort El, Zaldumbide A, Rombouts Y, Rispens T, et al. Identification and characterisation of citrullinated antigen-specific B cells in peripheral blood of patients with rheumatoid arthritis. Ann Rheum Dis. 2015 10.1136/annrheumdis-2014-207182

41. Bologna L, Gotti E, Manganini M, Rambaldi A, Intermesoli T, Introna M, et al. Mechanism of action of type II, glycoengineered, anti-CD20 monoclonal antibody GA101 in B-chronic lymphocytic leukemia whole blood assays in comparison with rituximab and alemtuzumab. J Immunol. 2011;186:3762-9.

42. Melis JP, Strumane K, Ruuls SR, Beurskens FJ, Schuurman J, Parren PW. Complement in therapy and disease: regulating the complement system with antibody-based therapeutics. Mol Immunol. 2015;67(2 Pt A):117-30.

43. Süsal C, Kirschfink M, Kropelin M, Daniel V, Opelz G. Identification of complement activation sites in human immunodeficiency virus type-1 glycoprotein gp120. Blood. 1996;87:2329-36.

44. Aletaha D, Neogi T, Silman AJ, Funovits J, Felson DT. Bingham 3rd CO, et al. Rheumatoid arthritis classification criteria: an American College of Rheumatology/European League Against Rheumatism collaborative initiative Arthritis Rheum. 2010;62:2569-81.

45. Babos F, Szarka E, Nagy G, Majer Z, Sarmay G, Magyar A, et al. Role of N- or C-terminal biotinylation in autoantibody recognition of citrullin containing filaggrin epitope peptides in rheumatoid arthritis. Bioconjug Chem. 2013:24:817-27.

46. Kiss E, Schnoller D, Pribranska K, Hill K, Penzes CB, Horvati K, et al. Nanoencapsulation of antitubercular drug isoniazid and its lipopeptide conjugate. J Disper Sci Technol. 2011;32:1728-34.

47. Horvati K, Bacsa B, Kiss E, Gyulai G, Fodor K, Balka G, et al. Nanoparticle encapsulated lipopeptide conjugate of antitubercular drug isoniazid: in vitro intracellular activity and in vivo efficacy in a Guinea pig model of tuberculosis. Bioconjug Chem. 2014:25:2260-8.

48. Abu-Rish EY, Amrani Y, Browning MJ. Toll-like receptor 9 activation induces expression of membrane-bound B-cell activating factor (BAFF) on human B cells and leads to increased proliferation in response to both soluble and membrane-bound BAFF. Rheumatology. 2013;52:1190-201.

49. Jahnmatz M, Kesa G, Netterlid E, Buisman AM, Thorstensson R, Ahlborg N. Optimization of a human lgG B-cell ELISpot assay for the analysis of vaccine-induced B-cell responses. J Immunol Methods. 2013;391:50-9. 
50. Ioan-Facsinay A, el-Bannoudi $H$, Scherer HU, van der Woude D, Menard HA, Lora $\mathrm{M}$, et al. Anti-cyclic citrullinated peptide antibodies are a collection of anti-citrullinated protein antibodies and contain overlapping and non-overlapping reactivities. Ann Rheum Dis. 2011;70:188-93.

51. Ossipova E, Cerqueira CF, Reed E, Kharlamova N, Israelsson L, Holmdahl R, et al. Affinity purified anti-citrullinated protein/peptide antibodies target antigens expressed in the rheumatoid joint. Arthritis Res Ther. 2014;16:R167.

Submit your next manuscript to BioMed Central and we will help you at every step:

- We accept pre-submission inquiries

- Our selector tool helps you to find the most relevant journal

- We provide round the clock customer support

- Convenient online submission

- Thorough peer review

- Inclusion in PubMed and all major indexing services

- Maximum visibility for your research

Submit your manuscript at www.biomedcentral.com/submit 